Thorax (1975), 30, 669.

\title{
No demonstrable effect of S-carboxymethylcysteine on clearance of secretions from the human lung
}

\author{
M. L. THOMSON ${ }^{1}$, D. PAVIA ${ }^{1}$, C. J. JONES ${ }^{2}$, \\ and T. A. C. MCQUISTON ${ }^{3}$ \\ TUC Centenary Institute of Occupational Health, London School of Hygiene and Tropical Medicine ${ }^{1}$, \\ A. H. Robins Co. Ltd, Redkiln Way, Horsham, Sussex ${ }^{2}$, and Tottenham Chest Clinic, St. Ann's General \\ Hospital, London N15 $3 T H^{3}$
}

\begin{abstract}
Thomson, M. L., Pavia, D., Jones, C. J., and McQuiston, T. A. C. (1975). Thorax, 30, 669-673. No demonstrable effect of S-carboxymethylcysteine on clearance of secretions from the human lung. The mucolytic efficacy of S-carboxymethylcysteine has been assessed in a double-blind crossover trial in 16 patients with chronic obstructive bronchitis. No significant difference was found between drug and placebo after four or seven days' treatment in the rate of clearance of secretions from the lung. This was measured by external counting of previously inhaled polystyrene tracer particles tagged with technetium-99m $\left({ }^{99 \mathrm{~m}} \mathrm{Tc}\right)$. Lateral scans across the right chest after inhaling the aerosol showed equal penetration of particles towards the periphery of the lung in drug and placebo runs; this indicated that the airways had not been cleared of mucus by the drug. There was no significant difference between drug and placebo runs in the number of coughs or the weight and radioactive content of sputum voided or raised at the end of the run by chest percussion and postural drainage. Ventilatory capacity was not significantly changed nor was there any subjective improvement in the patients as a result of taking the drug.
\end{abstract}

S-carboxymethylcysteine (L-3-[(carboxymethyl)thio]alanine; SCMC) is a derivative of the amino acid cysteine in which the sulphydryl (SH) group has been blocked by a carboxylic acid residue. Despite this it is said to possess with acetyl cysteine (Sheffner $e t$ al., 1964) and other compounds with free sulphydryl groups the ability to split the disulphide bonds of the long chain glycoproteins of mucus and thereby reduce its viscosity; it may also reduce the density of the fibrillar structure of the mucus by replacing fucomucins by sialomucins (Havez et al., 1970). Recently introduced into the United Kingdom, SCMC has been promoted as an effective respiratory mucolytic in chronic obstructive bronchitis when administered orally.

Although few double-blind trials have been done, most authors have reported reduced sputum viscosity by Brookfield viscometer (Autran, Bowtin, and Kleisbaur, 1970; Edwards, Steel, and Leszcynski, 1970) or increased pourability (Aylward, 1973) in chronic obstructive bronchitis during both relapse and remission after taking the drug (2.0-2.5 $\mathrm{g} /$ day). There is less agreement about the effect on sputum production (Edwards et al., 1970; Lemercier et al., 1970; Aylward, 1973; Aylward, 1974) or ventilatory capacity (Lemercier et al., 1970; Aylward, 1973;
Aylward, 1974) but most authors have noted subjective and objective clinical improvement in a variable proportion of their subjects. Patients with all types of sputum responded to the drug but those with mucoid or mucopurulent sputum were more affected in one study (Autran et al., 1970) while in another a change from purulent to mucoid sputum during treatment was reported (Sadoul, 1970).

We report below the effect of S-carboxymethylcysteine on mucociliary clearance in chronic obstructive bronchitis in a double-blind crossover trial using a new objective method. The procedure and radioactive dose (maximum $80 \mu \mathrm{Ci}$ ) have been approved by the Isotopes Panel of the UK Medical Research Council, the Hospital for Sick Children (Great Ormond Street), the ethical subcommittee of this School, and by the United Kingdom Atomic Energy Authority Research Establishment, Harwell for participation by their own staff (Booker $e$ t al., 1967).

\section{PATIENTS AND METHODS}

PATIENTS Sixteen male patients with chronic obstructive bronchitis (Medical Research Council, 1965) took part in the study; four had chronic bronchitis 
with varying degrees of bronchospasm and eight had chronic bronchitis with radiological evidence of emphysema. Although the patients were not chosen specifically because of difficulty in raising phlegm, we have shown that patients similar to these are capable of responding to expectorant and mucolytic drugs (Thomson, Pavia, and McNicol, 1973; Thomson et al., 1974). Informed consent was obtained from each patient. All were in remission throughout the trial period. Their mean $( \pm 1 \mathrm{SD})$ age was $63.6 \pm 8.9$ years and height $1 \cdot 71 \pm 0.07$ metres. There were nine smokers and seven ex-smokers who had smoked on average 15270 pack-years. They had moderate to severe loss of ventilatory capacity as assessed by a dry bellows spirometer (Vitalograph): after a week without mucolytic drugs their mean $( \pm 1$ SD) forced vital capacity (FVC), forced expiratory volume in $1 \mathrm{sec}$ $\left(\mathrm{FEV}_{1}\right)$, and $\mathrm{FEV}_{1} / \mathrm{FVC}$ were respectively $2.42 \pm 0.75$ l. $(62 \cdot 0 \pm 17 \cdot 3 \%), 1 \cdot 09 \pm 0.38 \mathrm{l}$. $(37 \cdot 3 \pm 12 \cdot 7 \%)$, and $46 \cdot 2 \pm 11 \cdot 21$. $(68 \cdot 2 \pm 16 \cdot 9 \%)$. (The values in parentheses are percentages of predicted (Cotes, 1968).)

EXPERIMENTAL DESIGN Mucolytic and expectorant drugs were discontinued one week before the trial but other therapy was maintained throughout the trial period. In randomized double-blind order, four of the patients took $4 \mathrm{~g}$ per day in four doses of SCMC in syrup (Mucodyne) and four took the same quantity of syrup only, a placebo indistinguishable from the drug. The first trial run was done after seven days of these treatments. After a further seven days with placebo only, the drug/placebo routine was repeated in reverse order and a second identical trial run was done after seven days of treatment. The same procedure was followed throughout for the remaining eight patients save that treatment was cut from seven to four days by increasing the rest period from seven to $\mathbf{1 0}$ days. In addition, at the end of both trial runs, this latter group had chest percussion and postural drainage done by a qualified physiotherapist. Placebo was taken throughout all non-treatment periods and a last dose of drug or placebo was given in the morning before both trial runs. Since no significant differences were found between the four- and seven-day treatment groups, the findings from these were pooled before the final analysis of the results.

A fluorescent marker (fluorescein) (Editorial, Lancet, 1972), incorporated in both drug and placebo, was identified in the urine of all subjects on the days of the trial runs. Apart from the two baseline ventilatory capacity determinations all measurements were made during the day of the trial runs.

TRACER PARTICLES The method has been fully described (Thomson et al., 1974). The patients inhaled monodispersed $5( \pm 0.7 \mathrm{SD}) \mu \mathrm{m}$ particles of $\frac{\overrightarrow{\mathrm{S}}}{\mathrm{F}}$ polystyrene which had been tagged unleachably with등 $99 \mathrm{~m}$ Tc (Few, Short, and Thomson, 1970). The volume $\overline{\bar{c}}$ of aerosol inhaled at each breath was automatically $\vec{\nabla}$ cut off at $500 \mathrm{ml}$. The flow rate during inhalation (mean average $21.2 \pm 1.7 \mathrm{SD} 1 / \mathrm{min}$ ) was (fortu- $\omega$ itously) identical in drug and placebo runs. These $\overrightarrow{0}$ factors, especially the first, should be strictly con- $-\overrightarrow{-}$ trolled since they affect the depth of penetration of the $\vec{\omega}_{\mathcal{O}}$ particles (Booker et al., 1967) and therefore their $\vec{F}$ subsequent rate of clearance from the lung. After $\times$ inhalation, whole lung gamma counts were made at ${ }^{\omega}$ half-hourly intervals to 6 hours by $\mathrm{NaI}(\mathrm{Tl})$ scintil-o lation detectors: one detector was at the midpoint of the sternum and a second axially opposite in the $e_{0}^{\circ}$ seated subjects.

Initial depth of deposition of the particles was $\overrightarrow{{ }_{0}}$ recorded by rectilinear gamma scanning (Dawson et al., 1971) across the right lung at one-inch intervals $\Phi$ after inhaling the tracer particles.

\section{RESULTS}

WHOLE LUNG CLEARANCE Figure 1 shows for drug. and placebo runs the mean serial whole lung gammaO counts at half-hourly intervals as percentages of thes



FIG. 1. Mean clearance curves from the whole lung counts for 16 patients in placebo and drug runs. Also shown are standard errors (vertical bars $\pm 1 S E$ ), the paired $t$ values $N$ and probabilities at half-hourly intervals. (Right) the effectiv of physiotherapy in 8 patients.

initial counts after they had been corrected for radioactive background and decay. The vertical barse denote \pm 1 standard error. Paired $t$ values and proba bilities are shown below the figure. These differenceso were not significant. The mean fall in whole lung( counts for eight patients due to physiotherapy is indicated on the right. Again the differences between 
drug and placebo runs were not significant. The mean losses during physiotherapy expressed as percentages of the six-hour values (19.9 and $19.4 \%$ ) were almost the same in placebo and drug runs.

LUNG SCANS Figure 2 shows the initial depth of penetration of particles across the right lung for drug and placebo runs. For each subject the counts for
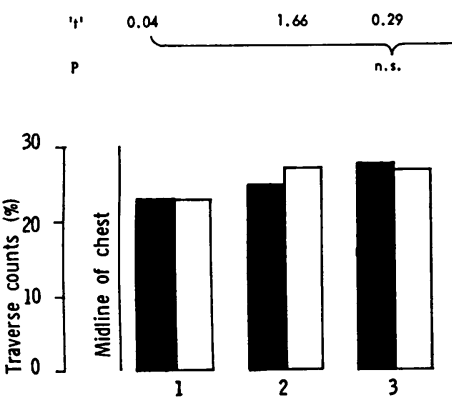

Distance from the midline of the chest ( inches

FIG. 2. Initial lateral distribution of inhaled tracer particles across the right lung. The heights of the columns represent for drug and placebo runs the means of the individual counts for each traverse of the scan expressed as percentages of the total scan counts. Also shown are the paired $t$ values and probabilities for each traverse.

each 1 in $(2.5 \mathrm{~cm})$ traverse have been expressed as percentages of the total count for all traverses: the heights of the columns are the means of these percentages for 16 patients. A rough index of penetration of the particles is obtained from the ratio of the sum of columns 1 and 2 (near the sternum) to the sum of columns 4 and 5 (near the periphery of the lung). There was no significant difference between drug and placebo runs in this penetration index $(t=0.52$; $P$ not significant) nor in the sums of the control $(t=0.67)$ or peripheral $(t=1 \cdot 00)$ pairs of columns.

VENTILATORY FUNCTION On average the FEV $\mathrm{F}_{1}$ fell by 10 and $30 \mathrm{ml}$ and the FVC rose by 60 and $50 \mathrm{ml}$ over the placebo and drug periods respectively. These differences were not statistically significant.

COUGH AND SPUTUM The Table shows for the drug and placebo runs the mean number of coughs and sputum samples and the mean weight and radioactive content of sputum voided during the runs. The difference between means was not significant nor was there any consistent pattern in these variables indicating any preponderance in drug or placebo runs. During placebo runs sputa were classified as 10 mucoid, one mucopurulent, and five purulent: in
T A B L E

MEAN ( + SE) NUMBER OF COUGHS AND SPUTUM SAMPLES AND THE SPUTUM WEIGHT AND RADIOACTIVITY FOR 16 PATIENTS FOR DRUG AND PLACEBO TRIAL RUNS TOGETHER WITH THE PAIRED $t$ VALUES AND PROB-

\begin{tabular}{|c|c|c|c|c|c|}
\hline & $\begin{array}{l}\text { No. of } \\
\text { Coughs }\end{array}$ & $\begin{array}{c}\text { No. of } \\
\text { Sputum } \\
\text { Samples }\end{array}$ & $\underset{\text { Weight }}{\text { Sputum }}$ & \multicolumn{2}{|c|}{$\begin{array}{c}\text { Sputum } \\
\text { Radioactive } \\
\text { Content } \\
\text { (counts) } \times 10^{3}\end{array}$} \\
\hline & $\mathbf{D}$ & D & D & $\mathbf{P}$ & D \\
\hline $\begin{array}{l}\text { Mean } \\
\text { SE }\end{array}$ & $\begin{array}{ll}53.7 & 77.7 \\
13.2 & 26.0\end{array}$ & $\begin{array}{ll}5.1 & 5.0 \\
1.0 & 0.9\end{array}$ & $\begin{array}{ll}8.7 & 7.5 \\
1.7 & 1.7\end{array}$ & $\begin{array}{r}108 \cdot 1 \\
26 \cdot 1\end{array}$ & $\begin{array}{r}107 \cdot 0 \\
22 \cdot 7\end{array}$ \\
\hline $\begin{array}{l}t \\
\text { Probability }\end{array}$ & $\begin{array}{c}1.46 \\
\mathrm{~ns}\end{array}$ & $\begin{array}{c}0.08 \\
\mathrm{~ns}\end{array}$ & $\begin{array}{c}0.93 \\
\text { ns }\end{array}$ & & $\begin{array}{l}.05 \\
\mathrm{~ns}\end{array}$ \\
\hline
\end{tabular}

$\mathbf{P}=$ placebo; $\mathbf{D}=$ drug.

the drug runs four were more purulent, three were less purulent, and nine were unchanged.

Physiotherapy on eight patients caused mean losses of sputum of 2.6 and $2 \cdot 1 \mathrm{~g}$ with 7400 and 16300 gamma counts for placebo and drug runs respectively; these differences did not differ significantly $(t=0.58$ and 0.43 ).

The answers to a questionnaire about dyspnoea, the quantity and stickiness of phlegm, and the ease with which it was raised were equivocal.

\section{DISCUSSION}

Although SCMC reduces sputum viscosity moderately in vitro (Hirsch, Viernes, and Kory, 1970) we have been unable to demonstrate that SCMC affects the fast phase rate of clearance of secretions from the lung in patients with chronic obstructive bronchitis.

The topographical distribution of inhaled tracer particles as obtained by rectilinear scanning was necessary for validating the whole lung clearance findings because the rate of clearance of particles varies inversely with the depth in the lung at which the particles are deposited (Thomson and Pavia, 1974). Peripheral mucus and the entrained particles have a longer transfer path to the larynx and, more important in dogs (Asmundsson and Kilburn, 1970) and almost certainly in humans, the inherent rate of transfer is much slower in the finer, than in the larger airways (Hilding, 1963). Moreover coughing is much less effective in expelling mucus from the small airways ( $<2 \mathrm{~mm}$ diameter) because adequate linear gas velocities are not achieved in the expanded peripheral airway bed (Leith, 1968). The close similarity in particle penetration shown here by the scans in drug and placebo runs indicates that 'the race of the particles to the larynx was fair'.

The failure of the tracer particles to penetrate deeper into the lung after four or seven days of treatment is retrospective evidence that the drug did 
not clear the airways before or between the trial runs. In a previous trial (Thomson et al., 1974) increased particle penetration was found after treatment with another mucolytic.

SPUTUM VISCOSITY In the study reported here there is no evidence that those patients with mucoid sputum showed more mucolysis than those with purulent sputum. Purulent sputum which is mainly composed of DNA fibres would not be expected to respond to double-bond-splitting agents such as SCMC.

It has long been known that there is a minimum mucus viscosity below which the cilia beat ineffectually, for example, in pandemic influenza (Hilding, 1943). Mucolytic agents might defeat their aim by reducing viscosity below this minimum (Carson, Goldhamer, and Carpenter, 1966): the dose used here (4 g/day) was higher than that recommended $(2 \cdot 0-2 \cdot 5 \mathrm{~g} /$ day $)$. Had the ciliary mechanism failed for this reason in the present trial, however, more low viscosity sputum would have been produced by physiotherapy in the drug than in the placebo runs, but this was not observed.

Sputum was collected here only over the six hours of the trial runs. During this time, however, the subjects were continuously under observation and every effort was made to ensure that all sputum raised was collected. Charman and Reid (1972) found no difference between early morning sputum and that obtained later in the day by physiotherapy, and it is unlikely that 24-hour collections would have shown major differences between drug and placebo volumes. Although increase in sputum production is commonly associated with decrease in viscosity, it is unlikely per se to result in better lung function (LopezVidriero et al., 1973).

EFFECT OF PHYSIOTHERAPY Chest percussion and postural drainage caused losses of activity from the lung which were greater on the average than those observed during the final three hours of the trial run. It would seem that during that three-hour period retention or 'pooling' of secretions must have occurred in the large airways in some subjects. If this is true, coughing must have been suppressed or ineffective, and in addition mucociliary transport must have been inadequate to overcome gravity. Presumably the postural change enabled gravity to be overcome or it stimulated coughing by altering the distribution of mucus. There was no evidence that this retention in the large airways was affected by the SCMC.

We thank Drs. G. Shneerson and M. S. M. Palmer of the Hampstead Chest Clinic for permitting us to study their patients; Miss R. Parker of the Brompton Hospital did the physiotherapy; Mr. A. Charters and Mr. P. Chapman constructed a gamma scanning apparatus. Berk Pharma-음 ceuticals Ltd. provided the SCMC and the placebo.

\section{REFERENCES}

Autran, P., Bowtin, C., and Kleisbaur, J. P. (1970). Clinical use of S-carboxymethylcysteine (5 per cent syrup) and its effect on fluidification of bronchiale secretions. Lyon Médical, 51, 1.

Aylward, M. (1973). A between-patient, double-blind $x$ comparison of S-carboxymethylcysteine and brom- $\omega$ hexine in chronic obstructive bronchitis. Current ${ }_{\circ}^{\circ}$ Medical Research and Opinion, 1, 219.

(1974). An assessment of S-carboxymethylcysteine in the treatment of chronic bronchitis. Currento Medical Research and Opinion, 2, 387.

Booker, D. V., Chamberlain, A. C., Rundo, J., Muir, D. C. F., and Thomson, M. L. (1967). Elimination of $\Phi$ 5 micron particles from the human lung. Nature,, $\mathbb{\infty}$ 215, 30 .

Carson, S., Goldhamer, R., and Carpenter, R. (1966). Mucus transport in the respiratory tract. American Review of Respiratory Diseases, 93, 86.

Cotes, J. E. (1968). Lung Function, 2nd edition. Blackwellor Scientific Publications, Oxford.

Dawson, H., Douglas, R. B., Pavia, D., Reeves, E., Short, M. D., and Thomson, M. L. (1971). An inexpensive automatic two-detector lung scanner. Physics ino Medicine and Biology, 16, 691 .

Editorial (1972). Cheek-pouches. Lancet, 1, 888.

Edwards, G. F., Steel, A. E., and Leszcynski, S. O. (1970) $\overrightarrow{7}$ The rheological effects of S-carboxymethylcysteines on sputum in chronic asthma and bronchitis Communication at 3rd International Congress of Allergology, Florence.

Few, J. D., Short, M. D., and Thomson, M. L. (1970) Preparation of ${ }^{99 \mathrm{mTc}}$ labelled particles for aeroso? studies. Radiochemical and Radioanalytical Letters, $5,275$.

Havez, R., Degand, P., Roussel, P., and Randoux, A (1970). Mode d'action biochemique des dérivés de lå cysteine sur le mucus bronchique. Poumon et le Coeur, 26, 81 .

Hilding, A. C. (1943). The relation of ciliary insufficiency to death from asthma and other respiratory diseases $\triangle$ Annals of Otology, Rhinology and Laryngology, 52, 5 을.

Hilding, A. C. (1963). Phagocytosis, mucous flow, and ciliary action. Archives of Environmental Health, 6,61 .

Hirsch, S. R., Viernes, P. F., and Kory, R. C. (1970) N Clinical and physiological evaluation of mucolytion agents nebulized with isoproterenol: 10 per cenf $\mathrm{N}$-acetylcysteine versus 10 per cent-2 mercaptoe thane sulphonate. Thorax, $25,737$.

Lemercier, J. P., Langlais, A., Michel, M. J., Laumonier R., and Metayer, J. (1970). Clinical trial of a new mucolytic, S-carboxymethylcysteine. $L^{\prime} Q u e s t$ Medi-O cal, 23, 411.

Leith, D. E. (1968). Cough. Physical Therapy, 48, 439.

Lopez-Vidriero, M. T., Charman, J., Keal, E., De Silva D. S., and Reid, L. (1973). Sputum viscosity 
correlation with chemical and clinical features in chronic bronchitis. Thorax, 28, 401.

Medical Research Council (1965). Definition and classification of chronic bronchitis for clinical and epidemiological purposes. Lancet, 1, 775.

Sadoul, P. (1970). Unpublished data.

Sheffner, A. L., Medlar, E. M., Jacobs, L. W., and Sarett, H. P. (1964). The in vitro reduction in viscosity of human tracheobronchial secretions by acetylcysteine. American Review of Respiratory Disease, 90, 721.

Thomson, M. L. and Pavia, D. (1974). Particle penetration and clearance in the human lung. Archives of Environmental Health, 29, 214.
- - _- Gregg, I., and Stark, J. E. (1974). Bromhexine and mucociliary clearance in chronic bronchitis. British Journal of Diseases of the Chest, 68, 21 .

$\longrightarrow,-$, and McNicol, M. W. (1973). A preliminary study of the effect of guaiphenesin on mucociliary clearance from the human lung. Thorax, 28, 747.

Requests for reprints to: Dr. M. L. Thomson, London School of Hygiene and Tropical Medicine, Keppel Street, London WC1E 7HT. 